\title{
Akut çıkıklara genel yaklaşım
}

\section{General approach to acute dislocations}

\author{
Nurzat Elmalı, Vahdet Uçan, Mehmet Kapıcıoğlu
}

Bezmialem Vakıf Üniversitesi Tıp Fakültesi, Ortopedi ve Travmatoloji Anabilim Dalı, İstanbul

\begin{abstract}
Travmatik çıkıklar en sık trafik kazaları, yüksekten düşmeler ve endüstriyel kazalarda, futbol ve bilek güreşi gibi sporlarda görülür. Akut çıkıklar sıklıkla omuz, dirsek, parmak, patella ve kalçada görülür. Çıkıklar nadir de olsa yaşamı veya ekstremiteyi tehdit edecek veya eklemde kalıcı fonksiyon bozukluğuna neden olabilecek ciddi komplikasyonlara neden olabilir. Yaralanmış eklemi ve olası çıkığı değerlendirirken, nörovasküler durumun değerlendirilmesi ilk ve en önemli adımdır. Etkilenen ekstremitede distal duyu, motor fonksiyon, kapiller dolum ve nabızlar hızlı ve dikkatlice değerlendirildikten sonra çıkıklar mümkün olan en kısa sürede redükte edilmelidir. Komplike olmayan akut çıkıklar için ilk tedavi genellikle intravenöz analjezi ve sedasyon ile kapalı redüksiyondur. Her redüksiyon manevrasından önce ve sonra ekstremitenin nörovasküler durumu değerlendirilir ve not edilir. Nabızda belirgin zayıflama varsa veya hiç alınamıyorsa arteriyogram gereklidir. Redüksiyon yapılsa bile çıkığa neden olan yüksek enerjili travma nedeniyle eklem kıkırdağı, kapsül ve bağ hasarı ve kemiğin kanlanmasındaki bozulmaya bağlı posttravmatik artrit, avasküler nekroz ve heterotopik ossifikasyon gelişebilir.
\end{abstract}

Anahtar sözcükler: çıkık; eklem çıkı̆̆ı; travma; redüksiyon
Traumatic dislocations are most commonly seen in road traffic accidents, falls from height, industrial accidents, and sports such as football and wrestling. The most common acute dislocations are seen in the shoulder, elbow, finger, patella, and hip. Serious complications of dislocations are unusual but may threaten life or limb viability, or cause permanent limb dysfunction. When evaluating any injured joint and possible dislocation, neurovascular status is the initial and most important step. Dislocations should be reduced as soon as possible after the affected extremity is assessed quickly and carefully for distal sensation, motor function, capillary pulse refilling, and pulses. Closed reduction with intravenous analgesia and sedation, or general anesthesia should be attempted first mostly for uncomplicated dislocations. Neurovascular condition of the extremity should always be assessed and noted before and after each reduction maneuver. Post-traumatic arthritis, avascular necrosis, and heterotopic ossifications may develop because of damage to the articular cartilage, joint capsule, ligaments, and vascularity of the bone due to high energy trauma even if reduction is made.

Key words: dislocation; joint dislocation; trauma; reduction

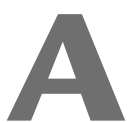

kut eklem çıkığı; ekleme gelen ani bir kurvet sonrası eklemleşen iki yüzeyin birbirinden tamamen ayrılmasıdır. Genellikle trafik kazaları, yüksekten düşmeler ve endüstriyel kazalarda, futbol ve bilek güreşi gibi sporlarda görülürken; dizde artmış $\mathrm{Q}$ açısı, patella alta gibi bilinen anatomik anormalliklerin varlığı çıkıklara zemin hazırlar. Eklem çıkıkları en sık 2060 yaşlarında ve erkeklerde daha sık (\%62) görülür. ${ }^{[1-5]}$ Beş yıllık sağkalımda tüm ortopedik çıkıkların sıklığı yıllık 100.000'de 42,1 olarak bildirilmiştir. ${ }^{[1]}$ Tüm çıkıkların yaklaşık \%75'i üst ekstremitededir. Omuz çıkığı tüm majör eklem çıkıklarının \%50'sini oluşturur ve bunların \%95'inden fazlası anteriora çıkıktır. ${ }^{[6]}$ Dirsek ikinci en sık çıkık görülen eklemdir. ${ }^{[7,8]}$ Parmak, patella ve kalça diğer sık görülen çıkıklardır. Diz çıkıkları oldukça nadirdir ve tüm çıkıkların sadece $\% 0,5^{\prime}$ idir. $^{[9]}$

Çıkıkların ampütasyon ve ölüm gibi ciddi morbidite ve mortaliteye neden olan komplikasyonları oldukça nadirdir, ancak yüksek hızlı motorlu taşıt kazalarında olduğu gibi majör damarlardan aktif kanama varlığında veya ciddi açık kırıklarla birlikte olduğunda yaşamı veya ekstremiteyi tehdit edebilir veya eklemde kalıcı fonksiyon bozukluğuna neden olabilir. ${ }^{[5]}$

Akut çıkıklar acildir. Yaralanmış eklemi ve olası çıkığı değerlendirirken nörovasküler durumun

- İletişim adresi: Prof. Dr. Nurzat Elmalı, Adnan Menderes Bulvarı, Vatan Cad. 34093, Fatih, İstanbul

Tel: 0532 - 4359129 e-posta: nelmali@hotmail.com

- Geliș tarihi: 9 Kasım 2018 Kabul tarihi: 9 Kasım 2018 
değerlendirilmesi ilk ve en önemli adımdır. Etkilenen ekstremitede duyu, motor fonksiyon, kapiller yeniden dolum ve distal nabızlar hızlı ve dikkatlice değerlendirildikten sonra, yumuşak doku yaralanması, eklem yüzey yaralanması ve nörovasküler yaralanma gibi potansiyel komplikasyonları azaltmak için, çıkık mümkün olan en kısa sürede redükte edilmelidir. ${ }^{[4]}$ Yaralanma ve redüksiyon arasındaki süre altı saati geçmemelidir. Her redüksiyon manevrasından önce ve sonra ekstremitenin nörovasküler durumu değerlendirilir ve not edilir. Özellikle diz ve kalça çıkıklarında hızla cerrahi onarım gerektiren nörovasküler yaralanma sıktır. Nabızda belirgin zayıflama varsa veya hiç alınamıyorsa arteriyogram gereklidir. ${ }^{[5]}$

Çıkıkların çoğunda sinir desteğinden zengin olan eklem kapsülünün gerilmesi veya yırtılması nedeniyle ciddi ağrı meydana gelir. Hasta, ağrı nedeni ile ekstremitesini hareket ettiremez. Ekstremitede deformite, çıkığın yönüne bağlı karakteristik pozisyon, şişlik, ekimoz bulunur. Çıkık sırasında nörovasküler yaralanmaya bağlı tam sinir ileti kaybı veya kalıcı nörit gelişebilir. En sıklıkla sinirlerde gerilme olur, haftalar veya aylar içerisinde iyileşebilen geçici motor ve/veya duyu defisiti oluşabilir. ${ }^{[5]}$

Fizik muayeneden sonra çıkığı ve eşlik eden kırıkları göstermede tanı genellikle düz grafiler ile konur. Çıkıklar distal parçanın yönüne göre tanımlanır. Posterior omuz çıkığının tanısını koymada skapula Y grafisi ve aksiller grafilerin tanıda yardımcı olması gibi, bazen özel pozisyonlarda grafiler gerekebilir. Dirsek çıkıklarında olası Monteggia kırıkları vb. atlamamak için el bileğini de içine alacak şekilde önkol grafileri mutlaka istenmelidir. Parçalı kırıklı çıkıklarda cerrahi düşünülen hastaların ameliyat planlamasında bilgisayarlı tomografi (BT) yararlıdır. Eşlik eden rotator manşet yırtığı gibi yumuşak doku lezyonları için elektif şartlarda manyetik rezonans (MR) görüntüleme istenilebilir.

Komplike olmayan akut çıkıklar için ilk tedavi genellikle intravenöz analjezi ve sedasyon ile kapalı redüksiyondur. Nörovasküler yapıyı etkilemeyen kapalı çıkıklar, özellikle hızlı redükte edildiklerinde ciddi komplikasyon riski çok azdır. Çıkıkların redüksiyonu genel olarak traksiyon/karşı traksiyon ve bazen rotasyon yöntemlerinin kombinasyonu uygulanarak sağlanır. Redüksiyon sırasında skopi kullanımı yardımcı olabilir. Kapalı redüksiyonda aşırı kuvvet uygulanmamalıdır. Yumuşak doku veya kemik bazen eklem yüzeyleri arasına girebilir ve kapalı redüksiyon mümkün olmayabilir. Çıkık redükte edilinceye kadar ağrı yeterince hafiflemez. Zaman geçtikçe şişlik ve kas spazmı redüksiyonu güçleştirir. Çıkık ilk saatler içerisinde redükte edilmediğinde stabil bir kapalı redüksiyon sağlamak imkansızlaşır. Genel anestezi verilecekse, hasta olası açık redüksiyon için de hazırlanmalıdır. Kapalı redüksiyonun başarılı olmadığı veya stabil bir redüksiyonun sağlanamadığı durumlarda açık redüksiyon gereklidir. Açık redüksiyon sırasında etkilenen sinir eğer direkt cerrahi alan içerisinde değilse siniri eksplore etmeye çalışılmamalıdır. Uygun bir süreden sonra iyileşme görülmezse sinir eksplore edilir. ${ }^{[5]}$

Açık redüksiyon endikasyonları; genel anestezi altında iken araya giren yumuşak dokular veya osteokondral parçalar nedeniyle kapalı yöntemlerle anatomik konsantrik redüksiyon sağlanamıyorsa veya stabil redüksiyon sürdürülemezse (eklem kırıklı çıkıkları sıklıkla instabildir ve stabiliteyi sağlamak için redüksiyonun tespit edilmesi gerekir), kapalı redüksiyondan önce nörolojik fonksiyon normal ve kapalı redüksiyondan sonra tam motor ve duyu kaybı belirgin ise, redüksiyondan önce yaralanmanın distalinde dolaşım bozukluğu tespit edilmiş ve redüksiyondan sonra devam ediyorsa açı redüksiyon gereklidir. Arteriyografi ile saptanan damar yaralanması varsa uygun tedavisi için cerrahi eksplorasyon gerekir. ${ }^{[5]}$ Çıkıklarla birlikte kırıklar sıktır. Başlangıç yaralanma anında olabileceği gibi, kapalı redüksiyon denemesi sırasında ayrılmamış kırık ayrılmış kırık haline gelebilir. Genellikle kırıkların açık redüksiyonu gerekir.

Açık veya kapalı redüksiyon yapılsa bile, çıkığa neden olan yüksek enerjili travma nedeniyle eklem kıkırdak hasarı ve kemiğin kanlanmasındaki bozulmaya bağı posttravmatik artrit, avasküler nekroz ve heterotopik ossifikasyon gelişebilir. ${ }^{[5]}$ Prognoz ve tedavi, çıkığın lokalizasyonuna ve yaralanmanın ciddiyetine bağlıdır.

\section{OMUZ ÇIKIĞI}

En sık öne çıkık görülür (>\%95). Sıklıkla uzatılmış el üzerine düşme veya abduksiyon - dış rotasyon zorlaması ile meydana gelir. Öne omuz çıkığında hastanın klasik pozisyonunda, kol dış rotasyonda ve hafif abduksiyondadır. Hastanın omuzu ağrılıdır ve hareket ettirmek istemez. Korakoid çıkıntının önünde humerus başı ele gelir (Şekil 1). Aksiller arter ve sinir hasarlanabilir. Aksiller sinir fonksiyonunun değerlendirilmesi, deltoid kontraksiyonunu hissetmekle veya kolun üst lateral kısmının duyu muayenesi ile yapılır. Supraskapuler sinir (\%29) ve radyal sinir (\%22) de etkilenebilir. ${ }^{[10]}$ Omuz çıkığı ile gelen hastada redüksiyon öncesi ve sonrası aksiller, ulnar, radyal ve median sinir muayeneleri yapılıp kayıt altına alınmalıdır. Omuz çıkıklarının yaklaşık \%25'ine tuberkulum majus kırığı eşlik eder.[11] Anterior omuz çıkığı sonrası Bankart ve Hill-Sachs lezyonları görülebilir. Özellikle yaşlılarda çıkık sonrası rotator manşet yırtıkları 

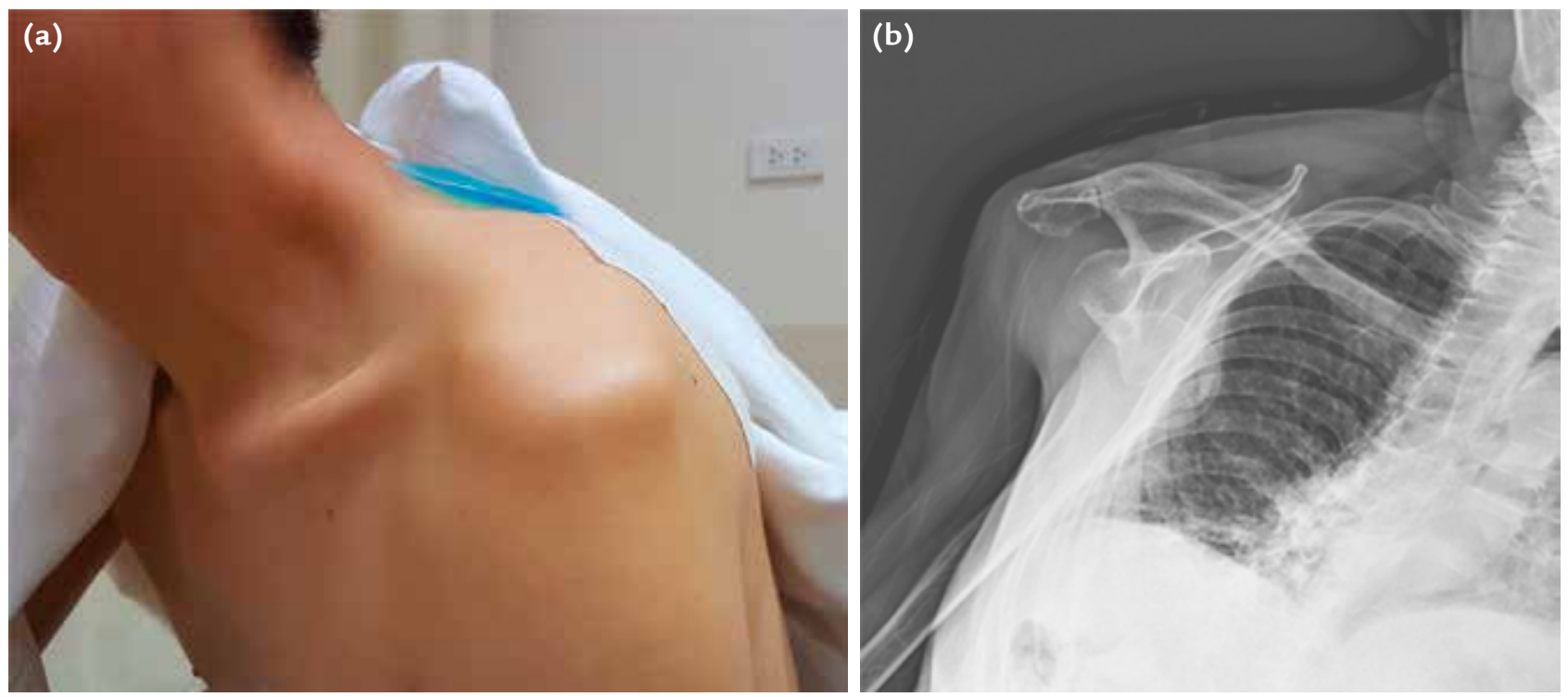

Şekil 1. a, b. Öne omuz çıkı̆̆ı: klinik (a) ve radyolojik (b) görünümler.

gelişebilir. ${ }^{[12]}$ Arkaya çıkık, omuz çıkıklarının \%2'sini oluşturur, sıklıkla epilepsi veya elektrik çarpmalarında adduksiyon ve iç rotasyon zorlamasıyla meydana gelir. Inferior çıkık (luxatio erecta) ise oldukça nadirdir $(\% 0,5)$, kol abduksiyonda kilitlenir. Hastanın eli baş seviyesinde tamamen abduksiyondadır. Humerus başı lateral göğüs duvarında palpe edilebilir. ${ }^{[13]}$

Omuz çıkı̆̆ı tanısı konulan hastaya en kısa süre içinde kapalı redüksiyon denenmelidir. Omuz çıkı̆̆ı için birçok redüksiyon manevrası vardır. Bu manevralar eklem içine lokal anestezik madde verilmesi (lidokain vb.) ve intravenöz anestezik ilaçlarla (midazolam, etomidat vb.) sedasyonun sağlanması ile yapılabilir. Sedasyon ile rotator manşet kaslarındaki spazm giderilir. Yapılan birçok çalışma, eklem içi lokal anestezinin kendi başına intravenöz sedasyona eşit olduğunu göstermiştir. ${ }^{[14,15]}$ Çok çeşitli redüksiyon yöntemleri vardır. Çarşaf yönteminde; kola traksiyonla birlikte hastanın gövdesi etrafına sarılan bir çamaşırla bir asistanın karşı yönde karşı traksiyon uygulaması redüksiyona yardımcı olur. Kocher manevrasında, omuz çıkığını redükte ederken humerus başını glenoidden kurtarmak için kola aksiyel traksiyonla birlikte abduksiyon ve dış rotasyon manevrası uygulanır. Kol baş üstüne abdukte edilince humerus başı redükte olur. Daha sonra kol adduksiyon ve iç rotasyona alınarak Velpau bandajı ile immobilize edilir. Stimpson tekniği, skapuler manipülasyon tekniği, Spaso tekniği, eksternal rotasyon metodu vb. başka redüksiyon yöntemleri de uygulanabilir.
İnferior çıkığın redüksiyonunda, bir asistan kontrtraksiyon uygularken baş üstü traksiyonla birlikte kol hiperabduksiyona getirilir. Daha sonra, kol adduksiyona alınırken humerus başını yukarı kaldırıcı baskı uygulanır. Olası iyatrojenik kırıkları atlamamak için, redüksiyon sonrası grafiler gereklidir.

Redüksiyon sonrası üç hafta kadar nötral rotasyonda omuz kol askısı kullanılır. Sonrasında, aktif yardımlı eklem hareket açıklığı ve izometrik güçlendirme egzersizleri yapılır. Genellikle 12. haftada kısıtlı bir şekilde spora dönüş yapılabilir. Hasta 16. haftadan sonra tolere edebilirse spora tam dönüş yapar. ${ }^{[10]}$

\section{DIRSEK ÇIKIĞI}

Tüm dirsek çıkıklarının yıllık insidansı 6,1/100.000'dir. ${ }^{[16]}$ Dirsek çıkıklarının \%90'ı posterior veya posterolateraldir (Şekil 2). Yaklaşık yarısı spor yaralanması sonucu oluşur. En sık, tam ekstansiyondaki kolun üzerine düşme sonucu oluşur. Hasta tipik olarak çıkık dirseğini fleksiyonda tutar. ${ }^{[16]}$ Eğer dirsekte anterior çıkık söz konusu ise dirsek ekstansiyon pozisyonundadır ve diğer ekstremiteye göre kısa görünür. Dirsek çıkıklarında önce sadece lateral kollateral bağ yaralanır. Daha ciddi yaralanmalarda, diğer lateral yapılar ve anterior/posterior kapsüler yapılar ve mediyal kollateral bağın yaralanması söz konusudur. Posterior dirsek çıkıklarında, mediyal ve lateral kollateral bağ yaralanmaları ile birlikte \%20-50 olasılıkla radius başı ve koronoidde kırık oluşabilir (terrible triad). ${ }^{[17]}$ 

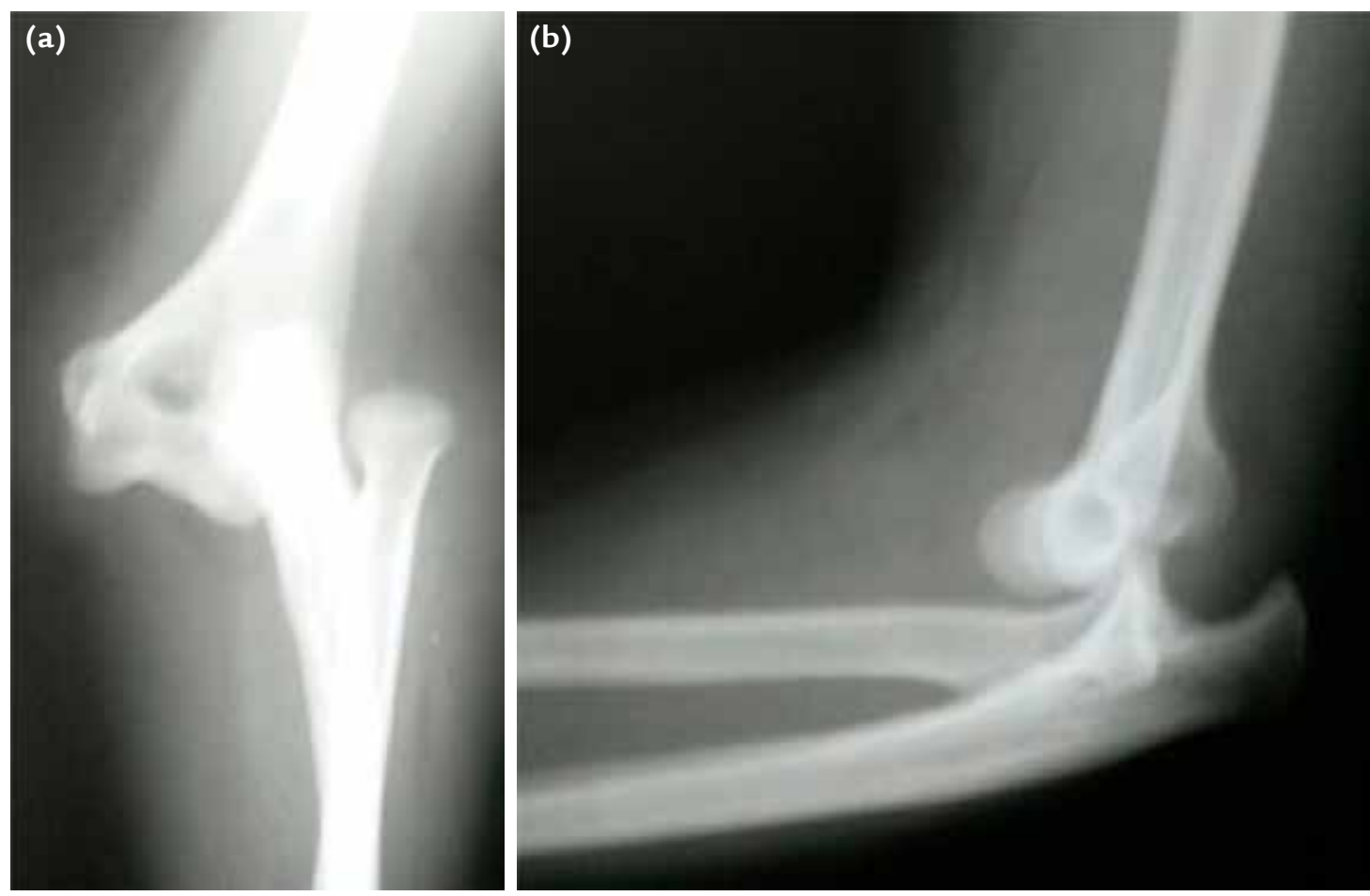

Şekil 2. a, b. Posterolateral dirsek çıkığı.

En sık görülen posterior dirsek çıkığında redüksiyon manevrası için tercih edilen pozisyon yüzüstüdür (pron). Uygun anestezi ve sedasyonu takiben, dirsek çıkığı olan ekstremite aşağıya sarkıtılır. Asistan koldan yukarıya doğru karşı traksiyon yaparken, redüksiyonu yapan hekim önce mediyolateral düzlemde olekranonu orta hatta getirir, sonra bir eliyle hastanın elini tutup traksiyon yaparken, diğer eliyle olekranonu trokleaya doğru baskı uygulayarak iter ve dirsek eklemini redükte eder.

Diğer bir yöntem olan supin pozisyonda, redüksiyon yapılırken bir asistan kolu başa yakın yerden tutar. Karşılıklı traksiyon eşliğinde dirsek yavaşça $90^{\circ}$ fleksiyona getirilir. Son olarak olekranondan kuvvet uygulanarak dirsek hiperfleksiyona getirilir. ${ }^{[17]}$ Dirsek redükte olunca eklemi stabilize etmek için önkol pronasyonda tutulur. Dirsek tipik olarak $90^{\circ}$ fleksiyonda immobilize edilir.

Eğer redüksiyon esnasında kuvvetli bir direnç ile karşılaşılırsa, fleksiyon için daha fazla kuvvet uygulanmamalıdır. Çünkü genelde koronoid parça kırılınca distal humerusa yerleşir. Kurvetli fleksiyon yapılırsa bu parça kırılabilir ve instabilite nedeni olabilir. Redüksiyon sonrası, posterior splint dirsek nötral rotasyonda ve $90^{\circ}$ fleksiyonda olacak şekilde uygulanır ve kontrol grafiler istenir. Birçok çalışmada, basit dirsek çıkığında erken mobilizasyon ile iyi sonuçlar bildirilmiştir. İmmobilizasyonun iki haftayı geçmemesine özen gösterilmelidir. ${ }^{[18]}$ Redüksiyon sonrası dirsek hareketleri değerlendirilmeli, dirsekte instabilite olup olmadığı kontrol edilmelidir. Varus/valgus stres testleri ile iç ve dış yan bağ muayeneleri yapılmalıdır.

\section{PARMAK ÇIKIKLARI}

Acil servise başvuruların \%2-28'ini oluşturur. ${ }^{[19]}$ Genç erkeklerde sıktır. Sıklıkla sporda topu yakalama sırasında aksiyel yüklenme ve hiperekstansiyona zorlanma ile meydana gelir. Dorsal PIP (proksimal interfalangeal) eklem çıkıklarında volar plak yırtılır (Şekil 3). ${ }^{[20]}$ Eğer PIP eklem çıkığı volar tarafa olursa bu durumda çoğu zaman dorsal plak, santral slip veya lateral bandın araya sıkışması sonucu kapalı redüksiyon gerçekleştirilemez. ${ }^{[21]}$

Parmak çıkıklarının redüksiyonunda genellikle lokal anesteziye ihtiyaç duyulur. Lokal anestezi öncesi nörovasküler muayene yapılmalıdır. Her parmağın radyal ve ulnar tarafinda seyreden dijital sinirlerin seyrine göre lokal anestezik enjeksiyonu yapılır. Dorsal dijital sinirler saat 10 ile 2 hizasından, palmar dijital sinirler ise 

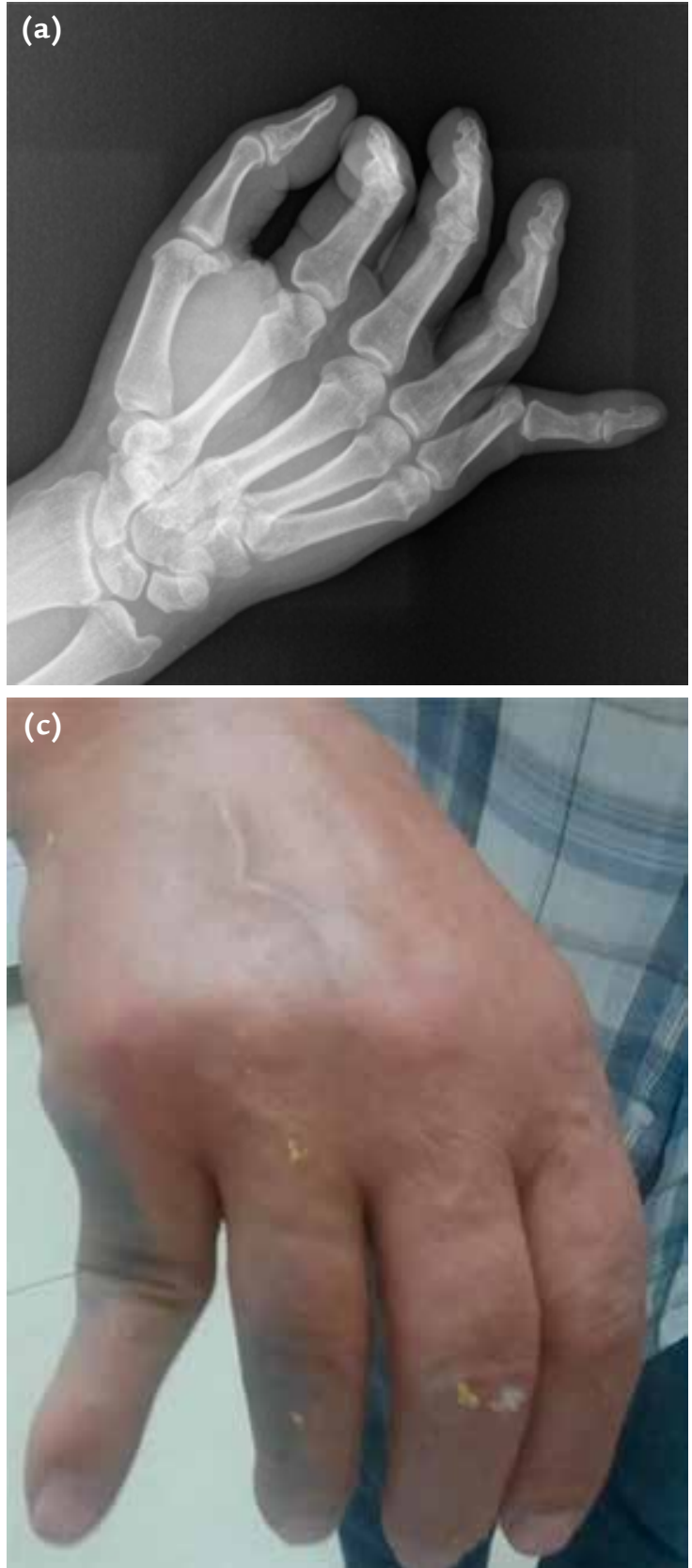

saat 4 ve 8 hizasından geçer. Lokal anestetik madde bu bölgelere verilir.

Daha sık görülen dorsal PIP çıkık için, PIP eklemin hiperekstansiyonu ve orta falanksın distal translasyonu tipik olarak eklemi redükte eder. Eğer çıkık redükte olmazsa, araya volar plak sıkışmıştır ve açık redüksiyon gerekir. Öte yandan redüksiyon sağlanmışsa hafif fleksiyonda buddy taping yapılıp kontrol grafisi istenir.

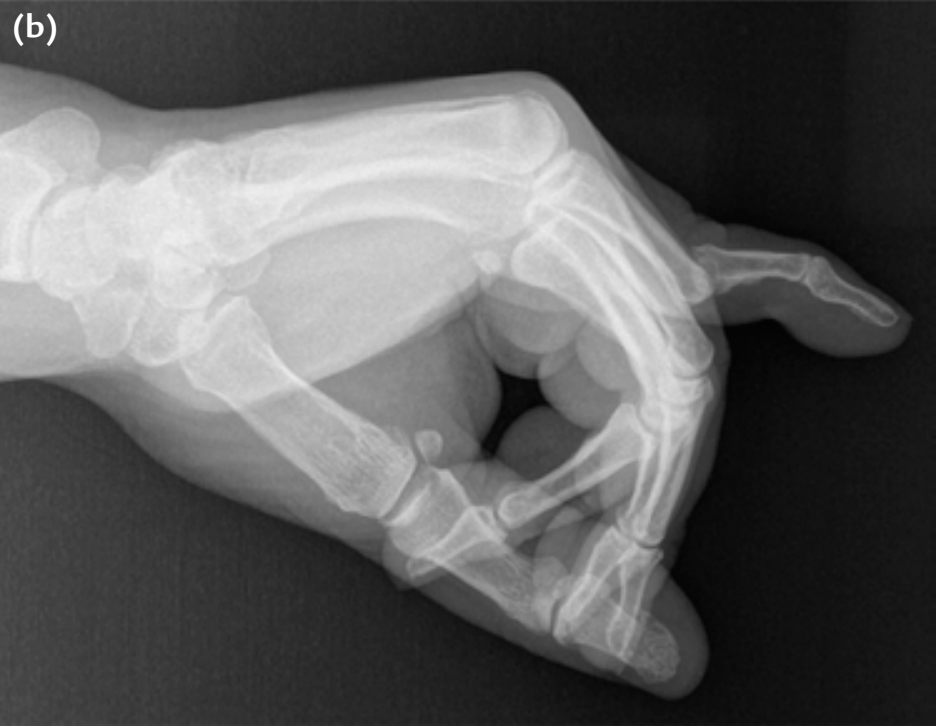

Şekil 3. a-c. PIP eklem dorsal çıkığı.

Dorsal PIP çıkıklarında nötral splintlemenin, splintleme sonrası görülen fleksiyon kontraktürü riskini azalttığı gösterilmiştir. ${ }^{[22]}$

Daha az görülen volar PIP ve DIP (distal interfalangeal) çıkıkları daha instabil çıkıklardır. Redüksiyon esnasında parmağa hafif aksiyel traksiyon yapılırken parmak fleksiyona getirilir. Ardından redüksiyon tamamlanana kadar parmağın tabanına kuvvet uygulanmalıdır. Redüksiyon sonrası kontrol grafisinde eklem uyumu ve eşlik eden olası kırıklar gözden geçirilir. Ardından kısa bir ekstansiyon splinti uygulanır. ${ }^{[22]}$ Basit çıkıklarda buddy taping yeterli iken kırıklı çıkık durumunda splint ile immobilizasyon gerekir.

\section{KALÇA ÇIKIKLARI}

Genellikle trafik kazaları gibi yüksek enerjili travmalar sonucu meydana gelir. Posterior çıkık en sıktır. Klasik mekanizma femurdan asetabuluma doğru olan aksiyel yüklenmedir. Araç içi trafik kazalarında kalça ve dizler fleksiyonda iken hastanın dizinin ön konsola çarpması sonucu olur. Kalça fleksiyon, iç rotasyon, adduksiyon pozisyonundadır. Bacak kısalmıştır. Anterior çıkık, abduksiyondaki bacağın hiperekstansiyona zorlanması ile meydana gelir. Kalça hafif fleksiyon, dış rotasyon ve abduksiyondadır. Bacak kısalmıştır. Pubik, obturator ve perineal tipleri tanımlanmıştır. Obturator çıkık nadir görülür (Şekil 4). ${ }^{[23-25]}$ Kalça çıkığına, asetabulum posterior duvar kırığı veya femur başı kırığı eşlik 

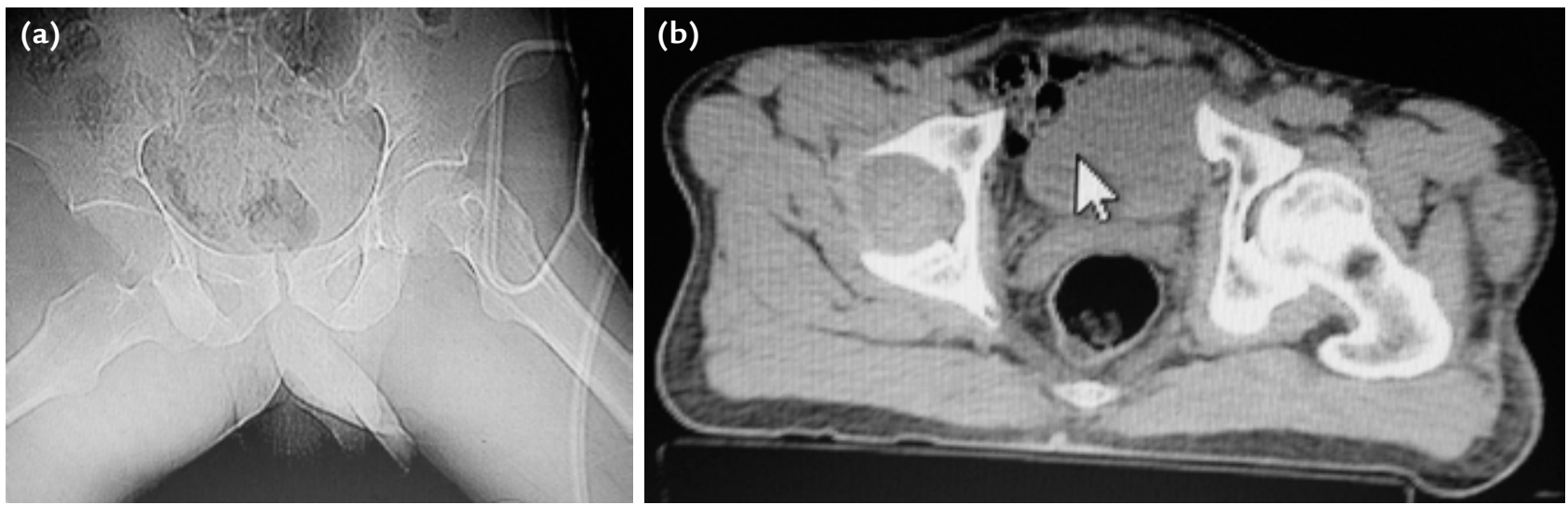

Şekil 4. a-c. Obturator çıkık.

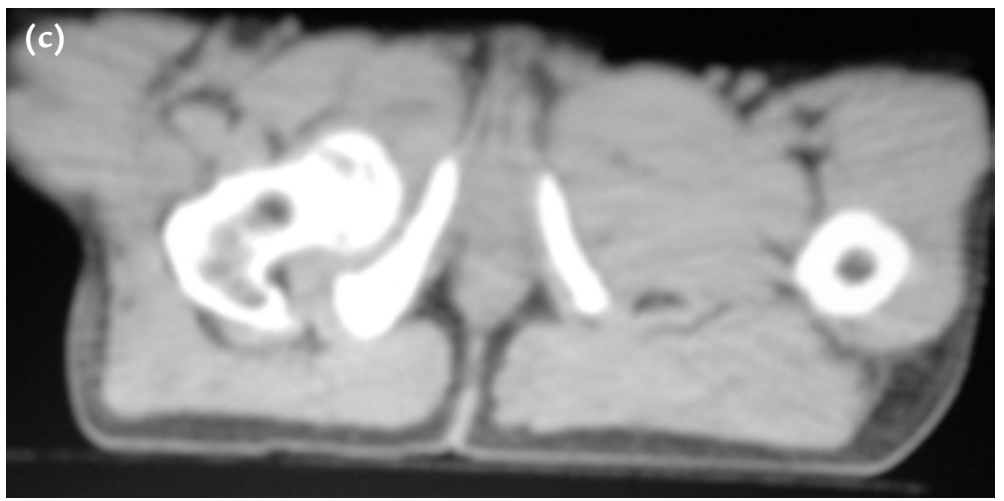

edebilir. Kalça çıkığı olan hastalarda, gizli kan kaybına bağlı hemorajik şok gelişebilir. Anterior kalça çıkığında femoral arter, ven ve sinir hasarı gelişebilir. Posterior kalça çıkığında hastaların \%13'ünde siyatik sinir yaralanması bildirilmiştir. ${ }^{[25]}$ Yine asetabulum posterior duvar kırığındaki kemik parçalar da siyatik sinire hasar verebilir. Özellikle kalçada dolaşımı yeniden düzenlemek ve avasküler nekroz komplikasyonundan kaçınmak için acil redüksiyon şarttır. ${ }^{[23]}$ ilk altı saat içinde redüksiyon yapıldığında femur başı avasküler nekroz (FBAN) sıklığı \%4,8 iken, daha geç kalındığında FBAN gelişme riski \%53 bulunmuştur. ${ }^{[23]}$ Kalça çıkıklarında komplikasyon, başlangıç travmanın şiddeti ile çıkığın uygun ve zamanında redüksiyonunun sağlanamaması ile ilişkilidir.

Hem anterior hem de posterior çıkığın redüksiyonu için birçok manevra mevcuttur. Hasta rahatı ve geniş kas gruplarının gevşemesi için intravenöz sedasyon gereklidir. Bunlardan Allis ve Bigelow metodları en bilinenleridir. Allis manevrasında, hasta supin pozisyonda uzanır. Hekim hastanın ayaklarının önündedir. Dizden bacağı kavrar ve femura aksiyel traksiyon uygularken diz $90^{\circ}$ fleksiyona getirilir. Bu arada bir asistan, her iki eli ile hastanın spina iliaka anterior superior
(SiAS)'undan karşı traksiyonla aşağı doğru bası uygular. Orijinal tanımında rotasyon yapılmaz. Kalça redükte olduğunda femur başının asetabuluma girmesini sağlamak için kalça nazikçe ekstansiyona ve dış rotasyona alınır. Kapalı redüksiyon sağlanmazsa açık redüksiyon yapılır. Kalçanın redüksiyonu grafilerle doğrulanır ve hasta kalçasını hafif abduksiyonda tutmak için bacakları arasına yastık yerleştirilir. Redüksiyonu, eklem içi parçaları ve herhangi bir kırığı değerlendirmek için BT yararlıdır. Yaralanmadan altı hafta sonra MR görüntüleme erken avasküler nekrozu değerlendirmek için yararlıdır. Hasta ağrısız yürüyene kadar koltuk değnekleri kullanmalıdır.

\section{Diz ÇıKıĞı}

Diz çıkıkları çok nadirdir ve genellikle yüksek enerjili travmaya bağlı görülür. Diz çıkıklarının çoğu hastayı klinik olarak muayene etmeden önce spontan redükte olduklarından, belirgin bir deformite olmayabilir ve tanı koymak zor olabilir. Sıklıkla olduğu gibi, trafik kazaları vb. yüksek enerjili travma sonucu multi-travmalı, şuuru kapalı hastada, özellikle spontan redüksiyon gerçekleşmişse tanı konması gecikebilir. ${ }^{[19,26]}$ Çoklu bağ yaralanması varlığında, şüphelenilmelidir. 


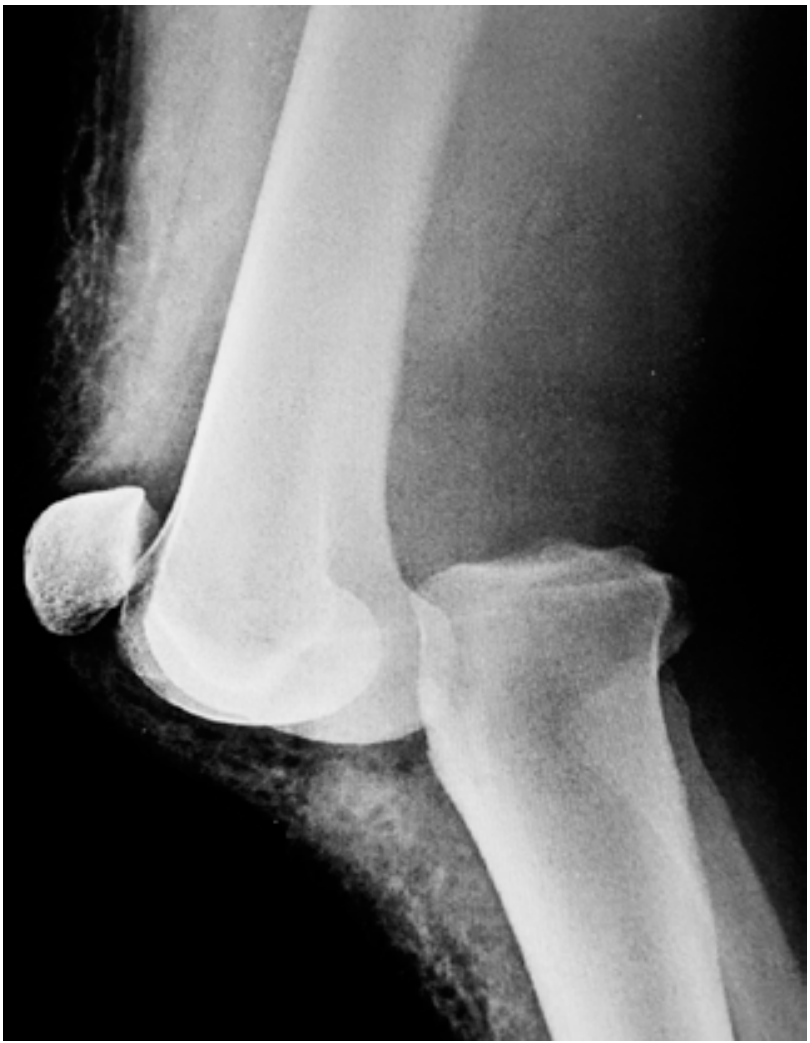

Şekil 5. Posterior diz çıkığı.

Femurun tibia ile ilişkisine göre diz çıkıkları, temel olarak anterior, posterior, mediyal, lateral ve rotasyonel olmak üzere beşe ayrılır. Rotasyonel çıkıklar da anteromediyal, anterolateral, posteromediyal ve posterolateral olmak üzere dört alt gruba ayrılır. ${ }^{[27]}$ En sık hiperekstansiyon yaralanmasına bağlı olarak anterior çıkık görülür (\%40), posterior çıkık 2. sıklıktadır (\%33) (Şekil 5). ${ }^{[19]}$

Diz çıkıklarında diğer çıkıklara göre özellikle nörovasküler yaralanma oranı yüksek olduğundan, bütün multi-travmalı hastalarda diz stabilitesi kontrol edilmelidir; instabilite varsa, ilk değerlendirmede vasküler muayene normal olsa bile, arteriyel duvarda intimal yırtığın genişlemesi veya damar oklüzyonu dolaşımı tehlikeye sokabilir. Bu dolaşım bozukluğu, yaralanmadan saatler sonrasına kadar klinik olarak gizli kalabilir. Şüphelenilmezse, eşlik eden popliteal arter yaralanmasının fark edilememesine ve hatta ekstremitenin kaybına bile neden olabilir. Popliteal arter yaralanması, travmatik diz çıkıklarının \%20 -40 'ında meydana gelen ve ekstremiteyi tehdit eden bir komplikasyondur. ${ }^{[28,29]}$ Bu nedenle, distal nabızlar redüksiyon yapılmadan önce ve sonra kontrol edilmelidir. Anterior çıkıklar arterde traksiyon lezyonu yaparken, posterior çıkıklar genellikle komplet yırtıklara neden olur. Nabızda zayıflama veya alınamaması durumunda arteriyografi ile hızlı değerlendirilmesini takiben cerrahi eksplorasyon gerekir. Popliteal arter yaralanması olan olgularda, revaskülarizasyon ilk 4-6 saatte yapıldığında amputasyon oranı yaklaşık \%11 iken, daha fazla gecikildiğinde \%86'ya çımaktadır. ${ }^{[29]}$ Peroneal sinir yaralanması posterior ve posterolateral diz çıkığında daha sıktır (\%16-40). ${ }^{30]}$ Redüksiyon yapılmadan önce ve sonra peroneal sinir kontrol edilmelidir.

Steril teknikle hemartrozun aspire edilmesinden sonra, redüksiyon için çıkığın yönüne bağlı olarak mediyal, lateral, anterior veya posterior yönde traksiyon uygulanır. Traksiyon sıklıkla dizi redükte edecektir. Amaç, ekstremiteyi ekstansiyonda tutmaktır. Redüksiyon sırasında nörovasküler yapılara ilave hasar vermemek için popliteal fossaya bası uygulamamaya dikkat edilmelidir. Mediyal femoral kondil üzerinde cildin gamzelenmesi, mediyal kapsülün araya sıkışması ile düğme deliği (button hole) deformitesinin oluşması kapalı redüksiyonu güçleştirir; açık redüksiyon gerekir (Şekil 6). ${ }^{[19]}$ Geniş yumuşak doku yaralanmalı veya damar onarımından sonra instabil olan açık diz çıkıklarında, dizi geçen eksternal fiksatörle başlangıç tespit uygulanabilir. Çoklu bağ yaralanmasının varlığında, genellikle ilk 2-3 hafta içerisinde bağ tamiri veya rekonstrüksiyonunu yapmak önerilir. ${ }^{[28]}$

\section{PATELLA ÇIKIĞI}

Görülme sıklığı yılda 77/100.000 olarak bildirilmiştir $^{[31]}$ ve bayanlarda daha sıktır. Troklear displazi, patella alta, $\mathrm{Q}$ açısının artması ve patellar tilt gibi altta yatan anatomik anormalliklere sık rastlanır. Adolesan sporcularda sıklıkla basketbolda ani dönme hareketi sonrası meydana gelir; hemartroz olur. Birçok patella çıkığı, hastaneye geliş esnasında dizin ekstansiyona gelmesi ile spontan veya muayene esnasında kendiliğinden redükte olur. ${ }^{[32]} \mathrm{Diz} 30^{\circ}$ fleksiyonda patellayı laterale ittirmek suretiyle yapılan korkutma testi pozitiftir. Hastada oluşan anksiyete ve direnç uygulama isteği testin pozitifliğini gösterir. Anterior-posterior (AP) ve lateral diz grafileri akut patella çıkığı şüphesinde ilk istenilecek grafilerdir. Akut patella çıkı̆̆ında, patellanın laterale translasyonunu engelleyen mediyal patellofemoral bağda yırtık oluşma sıklığı \%75-98

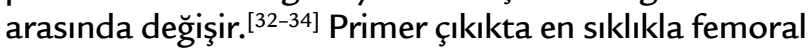
tutunma yerinden ayrılma görülür. ${ }^{[5]}$ Patellar çıkıklara \%5-71 oranında kondral veya osteokondral yaralanma eşlik eder. ${ }^{[33]}$ Olası osteokondral lezyonları değerlendirmek için grafiler dikkatlice incelenmelidir. Elektif şartlarda MR ile eşlik eden bağ yaralanmaları ve osteokondral lezyonlar değerlendirilebilir. Illk kez patella 

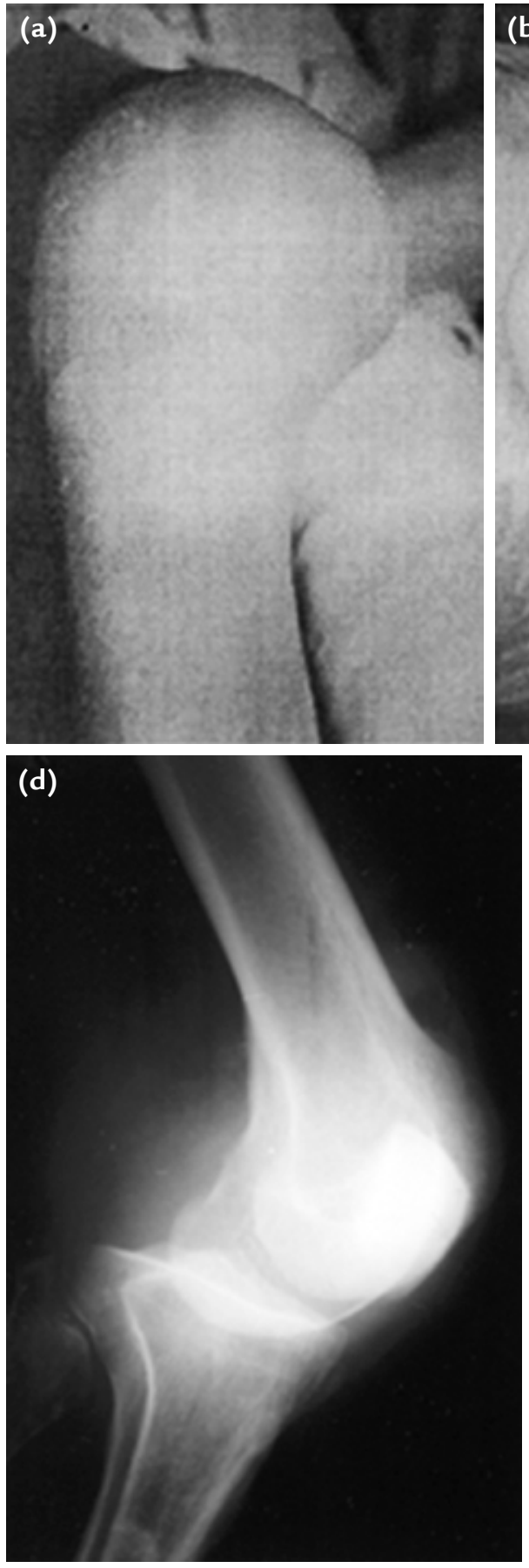
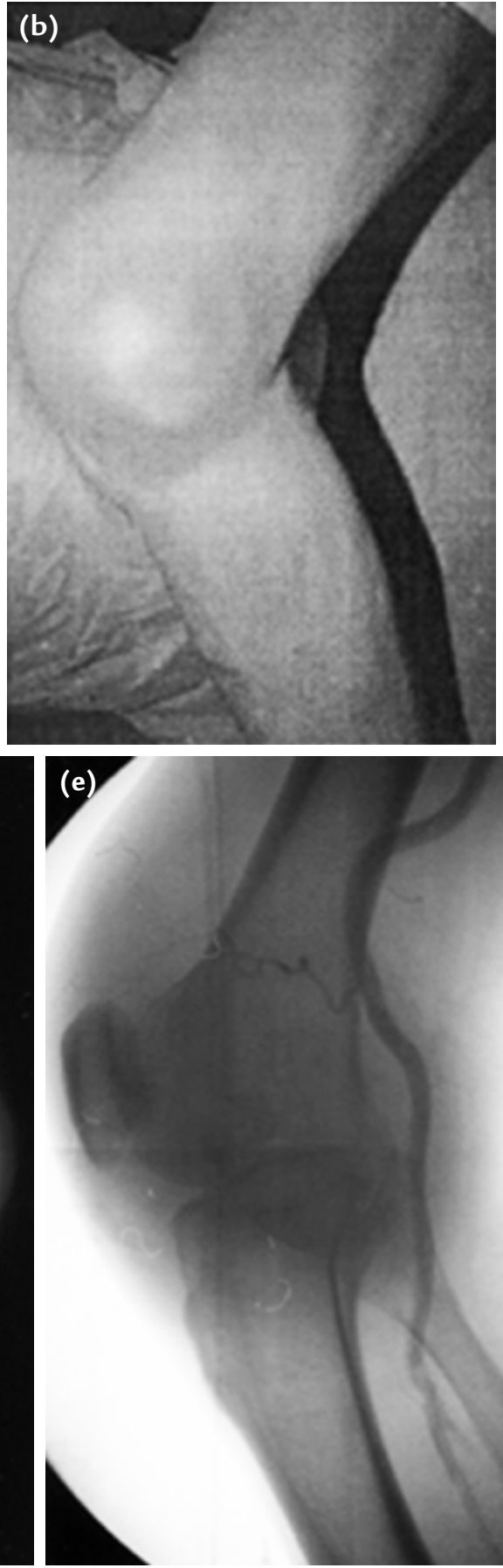

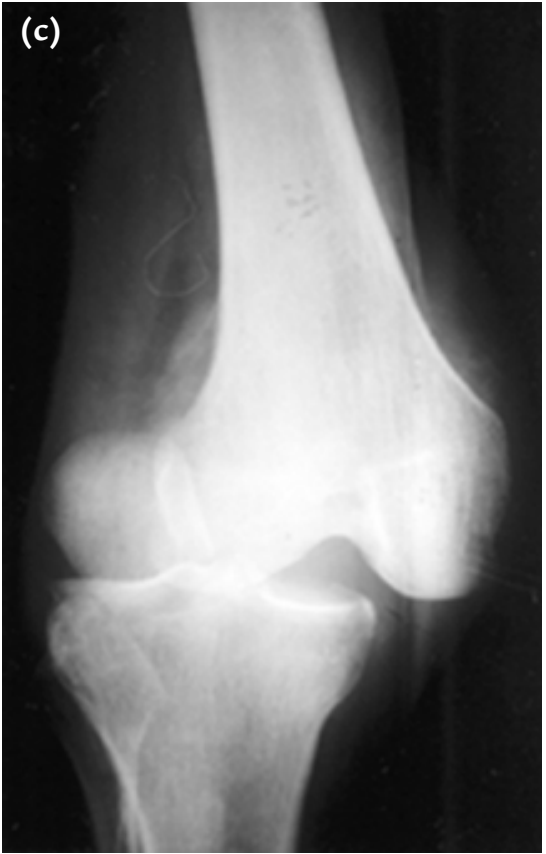

Şekil 6. a-e. Redükte edilemeyen posterolateral diz çıkı̆̆ı, medyal femoral kondilin düğme deliği deformitesi. çıkıkları, sıklıkla kapalı tedavi edilir. Redükte değilse, uygun analjezi ve sedasyon sağlandıktan sonra hasta supin veya oturur pozisyona ve kuadriseps kasının gerilimini azaltmak için diz fleksiyona getirilir. Ardından diz yavaşça ekstansiyona alınırken, patellanın lateralinden mediyale doğru kuvvet uygulanır. Bu esnada redüksiyon hissedilir. Ekstremite iki hafta immobilizer ile immobilize edilir ve hastanın tolere edebildiği kadar yük vermesine izin verilir. Redüksiyon, Merchant, AP ve lateral filmler ile kontrol edilir. ${ }^{[34]}$ Eklemde eşlik eden eklem faresi ile birlikte osteokondral kırık varlığında akut cerrahi müdahale yapılır. 

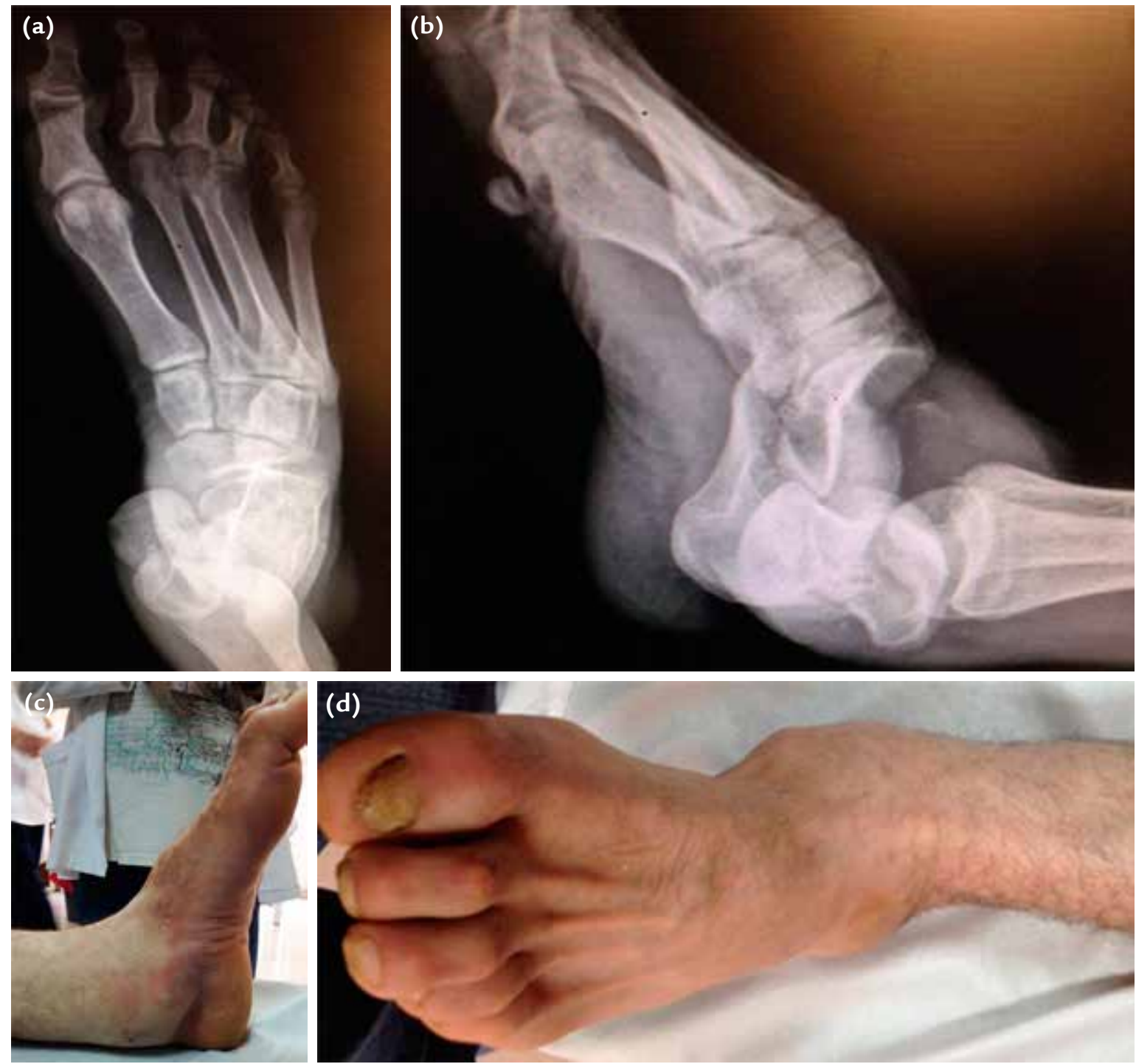

Şekil 7. a-d. Subtalar çıkık.

\section{AYAK BILEEĞi ÇIKIĞı}

Oldukça nadirdir; genellikle mediyal veya lateral malleol kırığı ile birliktedir. Kapalı yöntemle redüksiyonu genellikle kolaydır. Tibia arkasında fibulanın posterior çıkığı bazen kapalı redüksiyonu güç yapar ve açık redüksiyon gerekebilir. Deltoid bağ, anterior tibiotalar bağ ve anterior ve posterior talofibular bağlar tek başına veya kombine yırtılabilir. Kırık olmadığında akut bağ onarımı tartışmalıdır; ancak akut bağ onarımı yapılmayan hastalarda sonuçlar genellikle iyidir. Öte yandan, sindesmoz yaralanması varsa ve mortiste genişleme mevcutsa cerrahi yapılmalıdır. ${ }^{[5]}$ Subtalar çıkık oldukça nadir görülür (Şekil 7).

\section{SONUÇ}

Akut eklem çıkıkları, kırıklar kadar sık olmasa da acil servislerdeki ortopedi pratiğinde sıkça karşılaşılan durumlardır. Hangi eklem çıkığı olursa olsun, tanı konulması ile beraber kapalı redüksiyon uygulanmalıdır. Başarılı olunamaması halinde ameliyathane şartlarında açık redüksiyon yapılmalıdır. Redüksiyon öncesi ve sonrası nörovasküler muayene titizlikle yapılmalı ve kayıt altına alınmalıdır. Redüksiyon sonrası belli bir süre immobilizasyona alınan ekstremitenin fizik tedavi ile normal hareket açıklığına kavuşturulması esastır. 


\section{KAYNAKLAR}

1. Yang NP, Chen HC, Phan DV, Yu IL, Lee YH, Chan CL, Chou $P$, Renn JH. Epidemiological survey of orthopedic joint dislocations based on nationwide insurance data in Taiwan 2000-2005. BMC Musculoskelet Disord 2011;12(1):253. Crossref

2. Benjamin HJ, Hang BT. Common acute upper extremity injuries in sports. Clin Pediatric Emerg Med 2007;8(1):1530. Crossref

3. Skelley NW, McCormick JJ, Smith MV. In-game Management of Common Joint Dislocations. Sports Health 2014;6(3):24655. Crossref

4. Hodge DK, Safran MR. Sideline management of common dislocations. Curr Sports Med Rep 2002;1(3):149-55. Crossref

5. Masciolini AA.. Acute dislocations. In: Azar F, Canale ST, Beaty J, editors. Campbell's Operative Orthopaedics, 13th ed. USA: Elsevier Health Sciences; 2016. pp.3117-34.

6. Krøner K, Lind T, Jensen J. The epidemiology of shoulder dislocations. Arch Orthop Trauma Surg 1989;108(5):28890. Crossref

7. Kälicke T, Muhr G, Frangen TM. Dislocation of the elbow with fractures of the coronoid process and radial head. Arch Orthop Trauma Surg 2007;127(10):925-31. Crossref

8. Plancher KD, Lucas TS. Fracture dislocations of the elbow in athletes. Clin Sports Med 2001;20(1):59-76. Crossref

9. Sarıkaya $S$. Acil serviste ekstremite travmalı hastaya yaklaşım. Klinik Gelişim Dergisi 2008;21(4):90-100.

10. Wen DY. Current concepts in the treatment of anterior shoulder dislocations. Am J Emerg Med 1999;17(4):401-7. Crossref

11. Emond M, Le Sage N, Lavoie A, Rochette L. Clinical factors predicting fractures associated with an anterior shoulder dislocation. Acad Emerg Med 2004;11(8):853-8. Crossref

12. Tietjen R. Occult glenohumeral interposition of a torn rotator cuff: a case report. J Bone Joint Surg Am 1982;64(3):458-9. Crossref

13. Davids JR, Talbott RD. Luxatio erecta humeri. A case report. Clin Orthop Relat Res 1990;(252):144-9. Crossref

14. Moharari RS, Khademhosseini P, Espandar R, Soleymani HA, Talebian MT, Khashayar P, Nejati A. Intra-articular lidocaine versus intravenous meperidine/diazepam in anterior shoulder dislocation: a randomised clinical trial. Emerg Med J 2008;25(5):262-4. Crossref

15. Miller SL, Cleeman E, Auerbach J, Flatow EL. Comparison of intra-articular lidocaine and intravenous sedation for reduction of shoulder dislocations: a randomized, prospective study. J Bone Joint Surg Am 2002;84-A(12):2135-9. Crossref

16. Josefsson PO, Nilsson BE. Incidence of elbow dislocation. Acta Orthop Scand 1986;57(6):537-8. Crossref

17. Cohen MS, Hastings $\mathrm{H}$ 2nd. Acute elbow dislocation: evaluation and management. J Am Acad Orthop Surg 1998;6(1):15-23. Crossref

18. Ross G, McDevitt ER, Chronister R, Ove PN. Treatment of simple elbow dislocation using an immediate motion protocol. Am J Sports Med 1999;27(3):308-11. Crossref
19. Türker M, Ekșioğlu MF. Diz Çıkıkları: Güncel Kabuller ve Tedavi. Turkiye Klinikleri J Orthop \& Traumatol - Special Topics 2011;4(3):60.

20. Freiberg A. Management of proximal interphalangeal joint injuries. Can J Plast Surg 2007;15(4):199-203. Crossref

21. Inoue G, Maeda N. Irreducible palmar dislocation of the proximal interphalangeal joint of the finger. J Hand Surg Am 1990;15(2):301-4. Crossref

22. Incavo SJ, Mogan JV, Hilfrank BC. Extension splinting of palmar plate avulsion injuries of the proximal interphalangeal joint. J Hand Surg Am 1989;14(4):659-61. Crossref

23. Hougaard K, Thomsen PB. Traumatic dislocation of the hip - prognostic factors influencing the incidence of avascular necrosis of the femoral head. Arch Orthop Trauma Surg 1986;106(1):32-5. Crossref

24. Edomwonyi EO, Nwokike OC, Onuminya JE. Management of Traumatic Joint Dislocations in Irrua. Surg Sci 2015;6(3):11622. Crossref

25. Solomon L, Warwick D, Nayagam S. Injuries of the Hip and Femur. In: Solomon L, Warwick D, Nayagam S, editors. Apley's System of Orthopaedics and Fractures, 9th ed, Chap 29. Boca Raton: CRC Press; 2010. pp.843-74.

26. Engebretsen L, Risberg MA, Robertson B, Ludvigsen TC, Johansen S. Outcome after knee dislocations: a 2-9 years follow-up of 85 consecutive patients. Knee Surg Sports Traumatol Arthrosc 2009;17(9):1013-26. Crossref

27. Henrichs A. A review of knee dislocations. J Athl Train 2004;39(4):365-9.

28. Harner $\mathrm{CD}$, Waltrip RL, Bennett $\mathrm{CH}$, Francis $\mathrm{KA}$, Cole $\mathrm{B}$, Irrgang JJ. Surgical management of knee dislocations. J Bone Joint Surg Am 2004;86-A(2):262-73. Crossref

29. Wascher DC. High-velocity knee dislocation with vascular injury. Treatment principles. Clin Sports Med 2000;19(3):457-77. Crossref

30. Niall DM, Nutton RW, Keating JF. Palsy of the common peroneal nerve after traumatic dislocation of the knee. J Bone Joint Surg Br 2005;87-B(5):664-7. Crossref

31. Fithian DC, Paxton EW, Stone ML, Silva $P$, Davis DK, Elias DA, White LM. Epidemiology and natural history of acute patellar dislocation. Am J Sports Med 2004;32(5):1114-21. Crossref

32. Beasley LS, Vidal AF. Traumatic patellar dislocation in children and adolescents: treatment update and literature review. Curr Opin Pediatr 2004;16(1):29-36. Crossref

33. Elias DA, White LM, Fithian DC. Acute lateral patellar dislocation at MR imaging: injury patterns of medial patellar soft-tissue restraints and osteochondral injuries of the inferomedial patella. Radiology 2002;225(3):736-43. Crossref

34. Buchner $M$, Baudendistel B, Sabo D, Schmitt $H$. Acute traumatic primary patellar dislocation: long-term results comparing conservative and surgical treatment. Clin J Sport Med 2005;15(2):62-6. Crossref 